\title{
Effects of Modulus and Modifying Agent on Aging of Water Glass
}

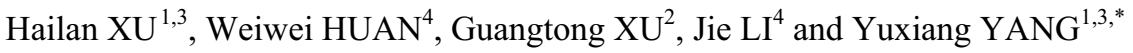 \\ ${ }^{1}$ School of Chemical and Environmental Engineering, Shanghai Institute of Technology, Shanghai, \\ 201418, China \\ ${ }^{2}$ State Key Laboratory of Catalytic Materials and Reaction Engineering (RIPP, SINOPEC) \\ ${ }^{3}$ East China University of Science and Technology, Shanghai, 200237, China* \\ ${ }^{4}$ Key Laboratory of Chemical Utilization of Forestry Biomass of Zhejiang Province
}

\begin{abstract}
This paper studied the content of water glass before and after adding modifying agent by TMS-GC method, it was found that different modulus of water glass led to decrease of silicate content at different levels after a period of storage, and the modifying agent could retard the aging of water glass. It has remarkable significance on the theory and practical application of water glass chemistry.
\end{abstract}

\section{Introduction}

There are several significant parameters on water glass, which directly affect the structure, composition, properties and the technological performance of water glass sand as binder. Due to reducing the bonding strength of water glass, the aging deteriorates directly affecting the economic benefit of water glass application ${ }^{[1]}$. In recent years, trimethylsilyl-gas-chromatography (TMS-GC method) have been used to determine the anionic constitution of silicate minerals, the big advantage of this system is to retain the original character of the structure while having not any request for the crystallinity of samples. Therefore, after the chemical analysis and diffraction method, TMS-GC becomes another effective method to study the structure of various silicate species. In this paper, the content of water glass before and after adding modifier was determined by TMS-GC method, and the changes of monomeric species and oligomeric silicate species after storage were also studied.

\section{Results and Discussion}

\subsection{Silylation method [2]}

$9 \mathrm{~mL} \mathrm{HCl}: \mathrm{H}_{2} \mathrm{O}(\mathrm{V} / \mathrm{V} 2: 1), 8.75 \mathrm{~mL}$ hexamethyl disiloxane and $1.25 \mathrm{~mL}$ internal standard solution $(2 \mathrm{~g} \mathrm{n}$-Tetradecane $/ 50 \mathrm{~mL})$ were added into $15 \mathrm{~mL}$ acetone and stirred vigorously for

* Corresponding author:yxyang@ecust.edu.cn 
30 minutes, then $10 \mathrm{~mL} 8.5 \mathrm{mmol}$ water glass samples were added into the mixture solution. After stirring for 90 minutes, the separated organic solution was washed repeatedly thrice, and then subject to ultrasonic treatment accompanying with $2 \mathrm{~g}$ of Amberlyst- 15 cation exchange resin for $1 \mathrm{~h}$, following filtered, and leaching solution as silylation derivative was analyzed by gas-chromatograph. The results are shown in Table 1 and Table 2.

\subsection{Effects of $\mathrm{SiO} / \mathrm{Na} 2 \mathrm{O}$ molar ratio on the total content of various silicate species that changes with aging time}

(1) It can be observed in Fig. 1 (originated from Table 1 and 2) that, with the modulus of water glass increasing, the contents of monomeric silicate species, Dimer, Cyclic-trimer, octamer, decamer, hexamer(a) and hexamer(b) all decreased accordingly, but the Trimer content reached a maximum value instead when the modulus of water glass was 2.4 . The total amount of oligomeric silicate species decreases as the modulus of water glass increases, which is due to the higher $\mathrm{SiO}_{2} / \mathrm{Na}_{2} \mathrm{O}$ molar ratio of water glass leading to a lower content of $\mathrm{Na}_{2} \mathrm{O}$ in water glass.

Because two different polymerization mechanisms occur in the water glass with different $\mathrm{SiO}_{2} / \mathrm{Na}_{2} \mathrm{O}$ molar ratios, the low $\mathrm{SiO}_{2} / \mathrm{Na}_{2} \mathrm{O}$ molar ratio probably causes the acidic polymerization mechanism; but the high $\mathrm{SiO}_{2} / \mathrm{Na}_{2} \mathrm{O}$ molar ratio probably causes the alkaline polymerization mechanism. The former leads to an increase of polymer species, and the latter leads to depolymerization of polymer species, consequently having relative high content of monomeric species and oligomeric silicate species.
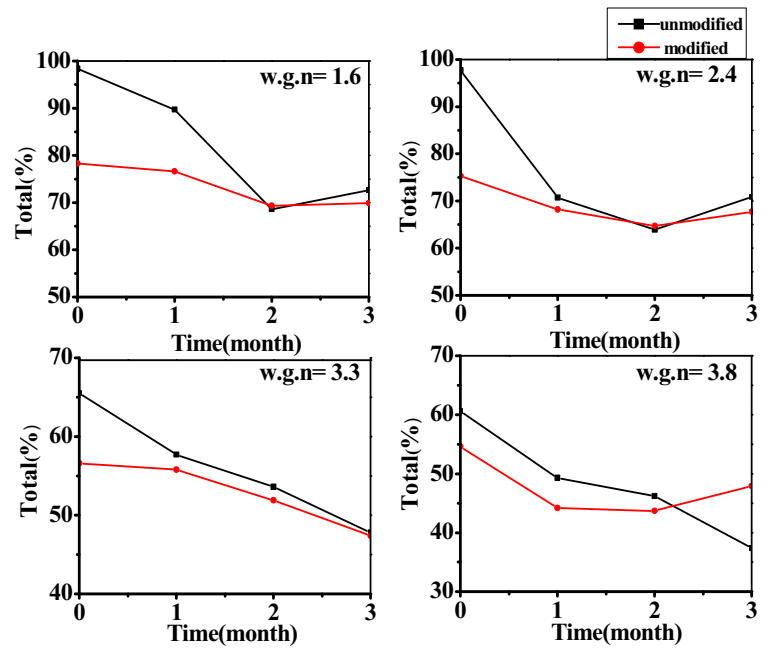

Fig. 1. Relationship between the content of silicate species and storage time

After the water glass was aged without modification, the contents of monomeric species, Cyclic-decamer, Cyclic-hexamer(a) and Cyclic-hexamer(b) all decreased, but the content of Dimer silicate species increased with aging time, then gradually decreased after storage for a month, while after storage for two months, the content of Dimer silicate species changed little. Furthermore, the contents of Cyclic-trimer and Cyclic-octamer silicate species decreased after storage for a month, but after storage for two months, the contents of them drew back. When the modulus of water glass reached 3.3 and 3.8, the total amount of oligomeric silicate species underwent changes $65.5 \rightarrow 57.7 \rightarrow 53.6 \rightarrow 47.8$ and $60.6 \rightarrow 49.3 \rightarrow$ $46.2 \rightarrow 37.4$ respectively, which basically continued downward trend. However, when the modulus of water glass decreased to 1.6 and 2.4, the total amount of oligomeric silicate species underwent changes $98.4 \rightarrow 89.7 \rightarrow 68.6 \rightarrow 72.6$ and $97.7 \rightarrow 70.7 \rightarrow 63.9 \rightarrow 73.9$ respectively, indicating that the total amount of oligomeric silicate species began to decrease 
with aging time until it dropped to minimum point after storage for two months, and then it drew back to 72.6 and 73.9 respectively. What's more, the change $\Delta$ for each modulus of water glass (unmodified) was calculated as: $\Delta_{1.6(\mathrm{uM})}=25.8, \Delta_{2.4(\mathrm{uM})}=23.8, \Delta_{3.3(\mathrm{uM})}=17.7$ and $\Delta_{3.8(\mathrm{uM})}=23.2$ respectively.

The contents of monomeric species and oligomeric silicate species decrease in the water glass aging process. Since water glass is a mixture of monomeric species, linear dimeric species, linear trimeric species and polymeric silicate species, silicate species would polymerize in the storage process, having many polymerization ways, such as monomeric species $\rightarrow$ monomeric species, monomeric species $\rightarrow$ oligomeric silicate species, oligomeric silicate species $\rightarrow$ polymeric silicate species, and so on. Therefore, the content of monomeric species and oligomeric silicate species will decrease after water glass aging.

Therefore, when the modulus is lower, the content of $\mathrm{Na}_{2} \mathrm{O}$ in water glass becomes higher, the water glass tends to undergo alkaline polymerization, and the content of oligomeric silicate species increases with aging time because of occurring of depolymerization ${ }^{[3]}$. Whereas, when the modulus is larger, the content of $\mathrm{Na}_{2} \mathrm{O}$ in water glass becomes smaller, the water glass tends to undergo acidic polymerization, and the content of oligomeric silicate species decreases with aging time because of further polymerization.

Table 1 The Content Of Each Component In The Unmodified Water Glass

\begin{tabular}{|c|c|c|c|c|c|c|c|c|c|c|c|c|c|c|}
\hline \multicolumn{3}{|c|}{ Sample } & \multicolumn{11}{|c|}{ Molar percent of component $(\%)$} & \multirow{2}{*}{$\begin{array}{l}\text { Total } \\
\left(\delta_{(\mathrm{uM})}\right) \\
)(\%)\end{array}$} \\
\hline $\begin{array}{l}\text { Storag } \\
\text { e time }\end{array}$ & $\begin{array}{c}\text { No } \\
\text {. }\end{array}$ & $\begin{array}{l}\text { Molar } \\
\text { ratio }\end{array}$ & $\begin{array}{l}\text { Mono } \\
\text { meric }\end{array}$ & $\begin{array}{c}\text { Dim } \\
\text { er }\end{array}$ & $\begin{array}{c}\text { Cyclic } \\
\text { trime } \\
\mathrm{r}\end{array}$ & \begin{tabular}{|c|} 
Cyclic- \\
tetram \\
er
\end{tabular} & $\begin{array}{c}\text { Trim } \\
\text { er }\end{array}$ & $\begin{array}{l}\text { Cyclic } \\
\text { octam } \\
\text { er }\end{array}$ & \begin{tabular}{|c|} 
Cyclic \\
hepta \\
mer
\end{tabular} & \begin{tabular}{|c|} 
Cyclic \\
decam \\
er
\end{tabular} & $\begin{array}{l}\text { Cyclic- } \\
\text { hexamer } \\
\text { (a) }\end{array}$ & $\begin{array}{c}\text { Cyclic- } \\
\text { hexamer } \\
\text { (b) }\end{array}$ & $\begin{array}{c}\text { Tetra } \\
\text { mer }\end{array}$ & \\
\hline \multirow{4}{*}{$\begin{array}{c}\text { Jus } \\
\mathrm{t}\end{array}$} & 1 & 1.6 & 55.9 & 6.7 & & & 10.5 & 3.6 & & 10.9 & 5.4 & 5.4 & & $\begin{array}{c}98 . \\
4\end{array}$ \\
\hline & 2 & 2.4 & 52.5 & 6.7 & & & 14.1 & 2.7 & & 10.9 & 5.4 & 5.4 & & $\begin{array}{c}97 . \\
7\end{array}$ \\
\hline & 3 & 3.3 & 50.4 & 4.3 & l & / & 3.4 & 1.7 & & 4.9 & 0.4 & 0.4 & & $\begin{array}{c}65 . \\
5\end{array}$ \\
\hline & 4 & 3.8 & 38.6 & 4.5 & l & / & 3.6 & 1.7 & & 5.4 & 4.0 & 2.8 & & $\begin{array}{c}60 . \\
6\end{array}$ \\
\hline \multirow[t]{4}{*}{$\begin{array}{c}\text { A } \\
\text { month }\end{array}$} & 1 & 1.6 & 49.1 & 15.5 & & & 11.3 & 3.6 & & 6.2 & 2.0 & 2.0 & & $\begin{array}{c}89 . \\
7\end{array}$ \\
\hline & 2 & 2.4 & 47.9 & 8.0 & & & 8.6 & 0.4 & & 4.4 & 0.7 & 0.7 & I & $\begin{array}{c}70 . \\
7 \\
\end{array}$ \\
\hline & 3 & 3.3 & 37.8 & 6.7 & & & \begin{tabular}{|l|}
4.2 \\
\end{tabular} & 1.7 & & 4.1 & 1.6 & 1.6 & & $\begin{array}{c}57 . \\
7\end{array}$ \\
\hline & 4 & 3.8 & 34.0 & 3.3 & I & & 6.3 & 0.2 & & 1.5 & 0.5 & 0.5 & & $\begin{array}{c}49 . \\
3\end{array}$ \\
\hline \multirow{4}{*}{\begin{tabular}{|c|} 
Two \\
month \\
$\mathrm{s}$
\end{tabular}} & 1 & 1.6 & 39.1 & 12.3 & & & 7.6 & 1.5 & & 5.9 & 1.1 & 1.1 & & $\begin{array}{c}68 . \\
6 \\
\end{array}$ \\
\hline & 2 & 2.4 & 35.3 & $\mid 10.7$ & & & \begin{tabular}{|l|}
6.7 \\
\end{tabular} & 0.8 & & 7.8 & 1.3 & 1.3 & & $\begin{array}{c}63 . \\
9\end{array}$ \\
\hline & 3 & 3.3 & 34.9 & 6.7 & & & 3.6 & 0.8 & & 5.4 & 1.1 & 1.1 & & $\begin{array}{c}53 . \\
6 \\
\end{array}$ \\
\hline & 4 & 3.8 & 28.6 & 4.3 & 1 & 7 & \begin{tabular}{|l|}
1.3 \\
\end{tabular} & 0.6 & 7 & 1.6 & 0.5 & 0.5 & & $\begin{array}{c}46 . \\
2\end{array}$ \\
\hline $\begin{array}{l}\text { Three } \\
\text { month }\end{array}$ & 1 & 1.6 & 36.8 & 12.6 & & & 10.5 & 3.4 & & 6.2 & 1.0 & 2.1 & & $\begin{array}{c}72 . \\
6\end{array}$ \\
\hline \multirow[t]{3}{*}{$\mathrm{s}$} & 2 & 2.4 & 30.7 & 12.6 & & & 10.5 & 3.5 & & 9.3 & 2.1 & 2.1 & & $\begin{array}{c}70 . \\
9\end{array}$ \\
\hline & 3 & 3.3 & 32.8 & 4.8 & & & \begin{tabular}{|l|}
2.9 \\
\end{tabular} & 0.8 & & 4.7 & 0.7 & 1.1 & & $\begin{array}{c}47 . \\
8\end{array}$ \\
\hline & 4 & 3.8 & 31.5 & 4.8 & & & 9.2 & 1.3 & & 4.1 & 1.1 & 1.1 & & $\begin{array}{c}37 . \\
4 \\
\end{array}$ \\
\hline
\end{tabular}


Table 2 The Content Of Each Component In The Modified Water Glass

\begin{tabular}{|c|c|c|c|c|c|c|c|c|c|c|c|c|c|c|}
\hline \multicolumn{3}{|c|}{ Sample } & \multicolumn{11}{|c|}{ Molar percent of component $(\%)$} & \multirow{2}{*}{$\begin{array}{c}\text { To } \\
\text { tal }\end{array}$} \\
\hline \begin{tabular}{|l|} 
Sto \\
rge \\
tim \\
$\mathrm{e}$
\end{tabular} & $\begin{array}{c}\text { No } \\
\text {. }\end{array}$ & $\begin{array}{c}\text { Molar } \\
\text { ratio }\end{array}$ & $\begin{array}{c}\text { Mon } \\
\text { ome } \\
\text { ric }\end{array}$ & $\begin{array}{l}\mathrm{Di} \\
\mathrm{me} \\
\mathrm{r}\end{array}$ & $\begin{array}{c}\text { Cyclic- } \\
\text { trime } \\
r\end{array}$ & $\begin{array}{c}\text { Cyclic- } \\
\text { tetram } \\
\text { er }\end{array}$ & $\begin{array}{c}\text { Tri } \\
\text { mer }\end{array}$ & $\begin{array}{c}\text { Cyclic- } \\
\text { octame } \\
\text { r }\end{array}$ & $\begin{array}{l}\text { Cyclic- } \\
\text { heptamer }\end{array}$ & $\begin{array}{l}\text { Cyclic- } \\
\text { decamer }\end{array}$ & $\begin{array}{l}\text { Cyclic- } \\
\text { hexamer } \\
\text { (a) }\end{array}$ & $\begin{array}{l}\text { Cyclic- } \\
\text { hexamer } \\
\text { (b) }\end{array}$ & $\begin{array}{c}\text { Tetra } \\
\text { mer }\end{array}$ & \\
\hline \multirow[t]{4}{*}{$\begin{array}{l}\text { Jus } \\
\mathrm{t}\end{array}$} & 1 & 1.6 & $\begin{array}{c}50 . \\
8\end{array}$ & 9.6 & & & 9.0 & 1.5 & & 4.6 & 0.5 & 2.3 & & $\begin{array}{c}78 \\
3\end{array}$ \\
\hline & 2 & 2.4 & $\begin{array}{c}46 . \\
6\end{array}$ & 8.8 & & & 8.2 & 0.9 & & 6.9 & 2.9 & 1.0 & 1 & $\begin{array}{r}75 \\
3\end{array}$ \\
\hline & 3 & 3.3 & $\begin{array}{c}39 . \\
5\end{array}$ & 5.9 & & & 3.4 & 1.1 & & 4.1 & 1.3 & 1.3 & & $\begin{array}{r}56 . \\
6\end{array}$ \\
\hline & 4 & 3.8 & $\begin{array}{c}36 . \\
1 \\
\end{array}$ & 6.1 & & & 3.8 & 1.0 & & 5.6 & 1.0 & 1.0 & / & $\begin{array}{r}54 \\
6 \\
\end{array}$ \\
\hline \multirow{4}{*}{$\begin{array}{c}\text { A } \\
\text { month }\end{array}$} & 1 & 1.6 & $\begin{array}{c}43 . \\
7\end{array}$ & 10.7 & & & 9.2 & 2.5 & & 7.8 & 2.0 & 0.7 & I & $\begin{array}{r}76 \\
6\end{array}$ \\
\hline & 2 & 2.4 & $\begin{array}{c}38 . \\
2\end{array}$ & 8.6 & & & 8.6 & 0.9 & & 7.4 & 0.7 & 3.8 & & $\begin{array}{c}68 \\
2 \\
\end{array}$ \\
\hline & 3 & 3.3 & $\begin{array}{c}37 . \\
8\end{array}$ & 6.0 & & & 3.7 & 1.1 & & 4.4 & 1.3 & 1.3 & 1 & $\begin{array}{r}55 \\
8\end{array}$ \\
\hline & 4 & 3.8 & $\begin{array}{c}35 . \\
3\end{array}$ & 3.2 & & & 1.7 & 0.6 & & 2.0 & 0.7 & 0.7 & 1 & $\begin{array}{r}44 \\
2\end{array}$ \\
\hline \multirow{4}{*}{\begin{tabular}{|c|} 
Two \\
month \\
$\mathrm{s}$
\end{tabular}} & 1 & 1.6 & $\begin{array}{c}39 . \\
5\end{array}$ & 14.4 & & & 8.0 & 1.3 & & 5.1 & 0.5 & 0.5 & & $\begin{array}{c}69 . \\
3\end{array}$ \\
\hline & 2 & 2.4 & $\begin{array}{c}37 . \\
8\end{array}$ & 8.0 & & & 2.9 & 1.1 & & 7.7 & 1.6 & 1.6 & & $\begin{array}{c}64 . \\
7\end{array}$ \\
\hline & \begin{tabular}{|l|}
3 \\
\end{tabular} & 3.3 & $\begin{array}{c}37 . \\
4 \\
\end{array}$ & 5.1 & 1 & 7 & 3.2 & 0.8 & 1 & 3.6 & 0.7 & 1.1 & & $\begin{array}{r}51 . \\
9 \\
\end{array}$ \\
\hline & 4 & 3.8 & $\begin{array}{c}33 . \\
2\end{array}$ & 3.7 & 1 & 1 & 2.3 & 0.8 & 1 & 2.3 & 0.7 & 0.7 & & $\begin{array}{r}43 \\
7 \\
\end{array}$ \\
\hline \multirow{4}{*}{\begin{tabular}{|c|} 
Three \\
month \\
$\mathrm{s}$
\end{tabular}} & 1 & 1.6 & $\begin{array}{c}37 . \\
0\end{array}$ & 14.2 & & & 9.2 & 1.3 & & 6.4 & 0.8 & 1.0 & & $\begin{array}{r}69 \\
9\end{array}$ \\
\hline & 2 & 2.4 & $\begin{array}{c}36 . \\
5\end{array}$ & 8.8 & & & 8.4 & 2.1 & & 7.7 & 2.1 & 2.1 & & $\begin{array}{r}67 . \\
7\end{array}$ \\
\hline & 3 & 3.3 & $\begin{array}{c}32 . \\
3\end{array}$ & 5.3 & & & 3.6 & 0.6 & & 3.8 & 0.8 & 1.0 & & $\begin{array}{r}47 . \\
4\end{array}$ \\
\hline & 4 & 3.8 & $\begin{array}{c}30 . \\
2\end{array}$ & 5.9 & & & 3.2 & 1.3 & & 3.1 & 2.1 & 2.1 & & $\begin{array}{r}47 . \\
9 \\
\end{array}$ \\
\hline
\end{tabular}

(2) In the initial stage of water glass prepared with modifying agent, the total content of monomeric species and oligomeric silicate species was significantly lower than that of pure prepared water glass, as shown in Fig. 3, while the total content of monomeric species and oligomeric silicate species of the modified glass with the modulus at 1.6 and 2.4 was significantly larger than that of the modified glass with the modulus at 3.3 and 3.8. It is because the modifying agent dispersed in water glass belongs to entropy model space stability type ${ }^{[4]}$, two or more dispersed particles would be pulled together by polyacrylamide for "creating the bridge", which led to polymerization of monomeric species and oligomeric silicate species, thus the entropy of system $\Delta_{\text {repel }}$ decreased, and the free energy $\Delta \mathrm{G}$ increased, it resulted in the system reaching a relatively stable state. The reason why aging rate of water glass decreased after adding the modifying agent could be found in above discussions. What's more, lower modulus of water glass would have higher $\mathrm{Na}_{2} \mathrm{O}$ in water glass, which led to alkaline polymerization; while higher modulus of water glass would have lower $\mathrm{Na}_{2} \mathrm{O}$ in water glass, which led to acidic polymerization. There probable existed the depolymerization of silicate species in water glass within high $\mathrm{pH}$ range in presence of higher 
$\mathrm{Na}_{2} \mathrm{O}^{[3]}$, which would lead to an increase of oligomeric silicate species, so lower modulus of water glass would cause the total content of monomeric species and oligomeric silicate species to increase. Another reason could be considered, namely, the lower modulus of water glass solution had higher $\mathrm{pH}$ value, and this might be more beneficial to the polyacrylamide "creating a bridge" mechanism.

(3) When the modulus of water glass was 1.6, the total content of monomeric silicate species and oligomeric silicate species changed little after storage for a month; however when the modulus of water glass was $2.4,3.3$ and 3.8, the total content of monomeric and oligomeric silicate species changed significantly.

By comparing Table 2 with Table 1, the total content of monomeric species and oligomeric silicate species in modified water glass was less than that in original water glass. When the modified water glass was aged for one month, two months and three months, the total amount of oligomeric silicate species underwent changes $78.3 \rightarrow 76.6 \rightarrow 69.3 \rightarrow 69.9$ for the modulus of water glass at $1.6,75.3 \rightarrow 68.2 \rightarrow 64.7 \rightarrow 67.7$ for the modulus of water glass at $2.4,56.6 \rightarrow 55.8 \rightarrow 51.9 \rightarrow 47.4$ for the modulus of water glass at 3.3 and $54.6 \rightarrow 44.2 \rightarrow 43.7 \rightarrow$ 47.9 for the modulus of water glass at 3.8 respectively. This means that change $\Delta$ for each modulus of water glass (modified) was calculated as: $\Delta_{1.6(\mathrm{M})}=8.4, \Delta_{2.4(\mathrm{M})}=7.6, \Delta_{3.3(\mathrm{M})}=9.2$ and $\Delta_{3.8(\mathrm{M})}=6.7$.

In contrast to the changes $\Delta_{(\mathrm{uM})}$ for unmodified water glass shown as $\Delta_{1.6(\mathrm{uM})}=25.8, \Delta$ $2.4(\mathrm{uM})=23.8, \Delta_{3.3(\mathrm{uM})}=17.7$ and $\Delta_{3.8(\mathrm{uM})}=23.2$, the modified water glass had less change $\Delta$ (uM) than those of unmodified water glass, indicating that the aging of water glass was retarded by adding modifier polyacrylamide. So above mentioned results can be both explained by thermodynamic stability of modified water glass, and by the DLVO theory ${ }^{[5-6]}$, which states that the dispersion stability of disperse system is the result of interaction dynamic forces between particles phases.

Because the modifier polyacrylamide is a nonionic polymer and the water glass is a dispersion system of monomeric species and oligomeric silicate species, when the modifier is adsorbed on the surface of silicate particles in water glass, the modifier forced the ions away from stern layer of silicate particles, leading to the diffuse double layers becoming thicker. So when two particles meet closely, the repulsion potential $V_{\text {repulsion }}$ increases with increase of superimposed parts of particles, so the Fan Dehua's attraction will be dominant when two particles meet. Therefore, the total potential energy barrier of the modified water glass system after being stored for a period is higher than that of unmodified water glass system, causing not easy polymerization reaction. So the total content of monomeric species and oligomeric silicate species in the modified water glass has smaller extent of decrease than those of the unmodified water glass after being stored for a period, that is to say, modifier polyacrylamide can delay the aging water glass.

\subsection{Effects of SiO2/Na2O molar ratio on the difference of total silicate species content between unmodified and modified water glass}

Plotting $\left(\delta_{(\mathrm{uM})}-\delta_{(\mathrm{M})}\right)$ versus modulus of water glass and plotting $\left(\delta_{(\mathrm{uM})}-\delta_{(\mathrm{M})}\right)$ versus aging time give the Fig. 2 and Fig. 3 respectively, where $\delta_{(\mathrm{uM})}$ and $\delta_{(\mathrm{M})}$ represent the total silicate species contents of unmodified water glass and modified water glass respectively at a certain modulus, from which we can draw the following conclusions:

(1) As can be seen from Fig. 2, when the modulus was 1.6 and 2.4, the water glass before and after modification had obvious differences, indicating maximum $\left(\delta_{(\mathrm{uM})}-\delta_{(\mathrm{M})}\right)$ value. Because the water glass underwent alkaline polymerization at low modulus, the modifier 
polyacrylamide could play the role of bridging between oligomeric silicate species, inducing the significant decrease of total silicate species content.

There is intimate relationship between $\left(\delta_{(\mathrm{uM})}-\delta_{(\mathrm{M})}\right)$ and modulus of water glass: with the increase of modulus, the $\left.\left(\delta_{(\mathrm{uM})}\right)_{(\mathrm{M})}\right)$ value decreased, and when modulus of water glass reached 3.8, the $\left(\delta_{(\mathrm{uM})}-\delta_{(\mathrm{M})}\right)$ value attained minimum value of -10.5 .

When the water glass was stored for one month, though the $\left(\delta_{(\mathrm{uM})}-\delta_{(\mathrm{M})}\right)$ value of water glass with modulus of 1.6 decreased to 13.1 , it still had obvious differences. The $\left(\delta_{(\mathrm{uM})}-\delta_{(\mathrm{M})}\right)$ values of water glass with modulus of $2.4,3.3$ and 3.8 all decreased to low value of $2.5,1.9$ and 5.1, respectively. When the water glass was stored for more than two months, water glass with modulus of 1.6 and 2.4 before and after modification had little difference. What's more, when the water glass was stored for more than three months, water glass with modulus of 3.3 and 3.8 before and after modification had little difference, which indicated all their $\left(\delta_{(\mathrm{uM})}-\delta_{(\mathrm{M})}\right)$ kept at low value within range $0.4 \sim-10.5$.
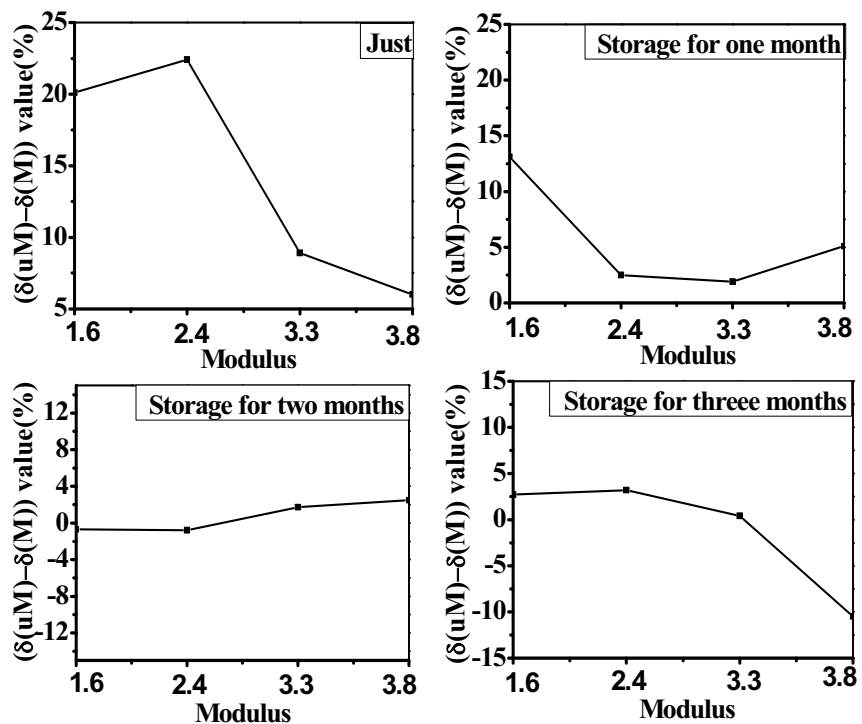

Fig. 2. Relationship between the difference that unmodified water glass minus modified water glass and difference specimens

(2) In contrast to Fig. 2, the change tendency of $\left(\delta_{(\mathrm{uM})}-\delta_{(\mathrm{M})}\right)$ value with aging time shown in Fig. 3 displayed some differences. When the water glass was just made, the $\left(\delta_{(\mathrm{uM})}-\delta_{(\mathrm{M})}\right)$ values of water glass with modulus of 1.6 and 2.4 had maximum value, higher than those of water glass with modulus of 3.3 and 3.8. With the storage time increasing, the $\left(\delta_{(\mathrm{uM})}-\delta_{(\mathrm{M})}\right)$ value of water glass with modulus of 1.6 decreased steadily, until after two months, and the draw-back of the $\left(\delta_{(\mathrm{uM})}-\delta_{(\mathrm{M})}\right)$ value from -0.7 to 2.7 occurred at three months of storage. The same observed phenomenon occurred on the $\left(\delta_{(\mathrm{uM})}-\delta_{(\mathrm{M})}\right)$ values of water glass with modulus of 2.4. This further demonstrates that when modulus of water glass was 1.6 and 2.4 in absence of modifier, the alkaline mechanism of polymerization took major role on the water glass, and the depolymerization of silicate species would lead to an increase of oligomeric silicate species in presence of higher $\mathrm{Na}_{2} \mathrm{O}^{[4]}$.

But when modulus of water glass was 3.3 and 3.8 , the $\left(\delta_{(\mathrm{uM})}-\delta_{(\mathrm{M})}\right)$ values all decreased straightly with the aging time, and the draw-back of the $\left(\delta_{(\mathrm{uM})}-\delta_{(\mathrm{M})}\right)$ value cannot be observed. This demonstrates that when modulus of water glass was 3.3 and 3.8 in absence of modifier, the acidic mechanism of polymerization took major role on the water glass, resulting in decrease of oligomeric silicate species. 

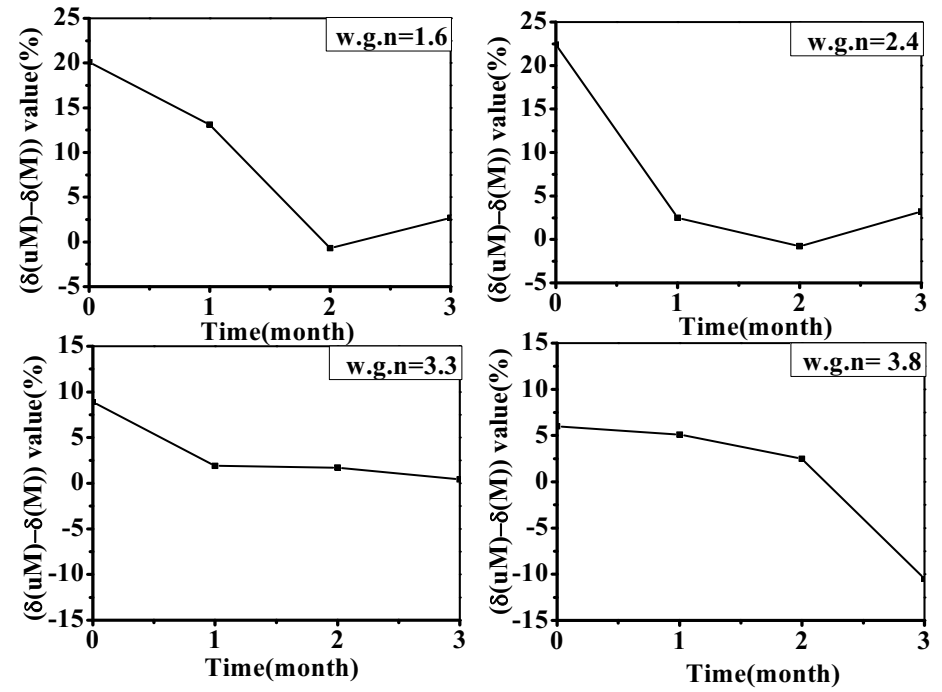

Fig. 3. Relationship between the difference that unmodified water glass minus modified water glass and storage for time

\section{Summary}

(1) The aging of water glass was that all sorts of silicate species in water glass formed high polysilicates with various polymerization methods.

(2) After adding chemical modifier into water glass, modifier firstly decreased the content of monomeric species and oligomeric silicate species by the "creating a bridge" mechanism, which maintained the system in a relatively stable state of dynamic balance. Later, the change of content of various silicate species was smaller than that in unmodified water glass in the storage process.

(3) Modifier polyacrylamide can delay aging by 1 2 months. As shown in the mechanism, physical modification can eliminate aging and chemical modification can retard aging, so we also carried out a chemical and physical modification test, namely using reflux and adding modifier of water glass. The result is that the content of oligomeric silicate species significantly increases than without the reflux, and the content of monomeric species also slightly increases, which indicates that the physical modification is equivalent to a reverse process of water glass aging, and that it can restore the water glass to the original state. Therefore, if the water glass is processed by chemical and physical modification, it will obtain delaying effect, which will open up a new field of water glass application.

\section{Acknowledgement}

The authors wish to express their appreciation to state key laboratory of catalytic materials and reaction engineering (RIPP, SINOPEC) for financial support. 


\section{References}

1. Soleimani Dorcheh, Journal of materials processing technology. 199(2008) 10-26.

2. Pan Ming Chu, Deng Wen Jing, Yang Yu Xiang, et al., Glass Physics and Chemistry. 36(2010)110-115.

3. LIU Li-na, FAN Yan, ZHENG Lin, LI Yong-jun, LIU Tong, et al., Chinese Journal of Experimental Traditional Medical Formulae. 20(2012)125-128.

4. Davidovits J. (1999) Chemistry of Geopolymeric SystemsGeopolymer 99 Proceedings: Second International Conference, France, July 1- 2, 1999. Saint Quentin: Universite de Picardie.

5. J.A.J. Meesters, A.A. Koelmans, J.T.K. Quik, A.J. Hendriks, and D. van de Meent, Environ. Sci. Technol. 48 (2014)5726-5736.

6. A.R. Petosa, D.P. Jaisi, I.R. Quevedo, Environ. Sci. Technol. 44(2010)6532-6549. 